7. Lưu AT. Nghiên cứu đặc điểm lâm sàng, nội soi, cắt lớp vi tính và mô bệnh học của viêm mũi xoang man tính có polyp. Published online 2018.

8. Acar A, Cayonu M, Ozman M, Eryilmaz A. Changes in Acoustic Parameters of Voice After Endoscopic Sinus Surgery in Patients with Nasal
Polyposis. Indian J Otolaryngol Head Neck Surg Off Publ Assoc Otolaryngol India. 2014;66(4):381-385.

9. Kim YH, Lee SH, Park CW, Cho JH. Nasalance change after sinonasal surgery: analysis of voice after septoturbinoplasty and endoscopic sinus surgery. Am J Rhinol Allergy. 2013;27(1):67-70.

\title{
KHẢO SÁT SỰ TUÂN THỦ THUỐC ĐIỀU TRI TĂNG HUYẾT ÁP Ở NGƯờI BỆNH TAI BIẾN MACH MÁU NÃO VÀ MộT SỐ YẾU TỐ LIÊN QUAN
}

\section{TÓM TẮT}

Mục tiêu: Khảo sát mức độ tuân thủ thuốc điều trị tăng huyết áp (THA) ở bệnh nhân tai biến mạch máu não (TBMN) có THA đồng thời phân tích một số yếu tố liên quan. Đối tượng \& Phương pháp nghiên cứu: Nghiên cứu cắt ngang mô tả, thức hiên từ 9/2020 6/2021 trên202 người bệnh TBMN có THA điều trị tại khoa Thần kinh, Bênh viển Bach Mai. Dữ liêuu được thi thập qua bệnh án và bộ câu hỏi phỏng vấn được thiết kế sẵn. Đánh giá tuân thủ điều trị thuốc dựa vào thang điểm Morisky-8. Kết quả: Tuổi trung bình của nhóm nghiên cứu là $65,13 \pm 11,54$, trong đó nam giới chiếm $55 \%$. Sự hiểu biết của người bệnh về THA ở các mức độ như kém, trung bình vàcao lần lượt là $20,8 \%$, $47,0 \%$ và 32,3\%. Điểm Morisky-8 trung bình là $4,93 \pm 1,97$. Tỷ lệ tuân thủ thuốc điều trị THA ở mức đô kém, trung bình và cao lần lượt là $59,9 \%, 31,7 \%$ và $8,4 \%$. Giới tính, tuổi, việc tham gia bảo hiếm y tế, hút thuốc lá thường xuyên, thời gian bị THA và sự hiểu biết của người bênnh vế THA là các yếu tố liên quan độc lập với việc tuân thủ thuốc điều trị THA. Kết luận: Sự kém tuân thủ thuốc điều trị THA ở nhóm người bểnh nghiên cứuchiếm tỷ lệ cao $(59,9 \%)$. Các yếu tố liển quan độc lập với sự tuân thủ điều trị THA được gh nhân gồm: nhóm tuổi trên 50, nữ giới, tham gia bảo hiểm y tế, không hút thuốc lá, thời gian mắc THA trên 5 năm và sư hiếu biết đầy đủ của người bênh về THA.

Tư khóa: Tuân thủ thuốc, Tai biến mạch máu não, Tăng huyết áp, Thang điểm Morisky-8

\section{SUMMARY}

INVESTIGATION OF MEDICATION

ADHERENCE TO ANTIHYPERTESIVE DRUGS

AND SOME RELATED FACTORS AMONG

HYPERTENSIVE STROKE PATIENTS

Objective: To investigate the medication adherence (MA)to antihypertensive drugs and to analyze some related factorsamong hypertensive stroke patients. Patients and methods: A cross-

\section{*Bệnh viện đa khoa tỉnh Ninh Binh}

**Trường Đai hoc Y Hà Nôi

Chiu trách nhiệm chính: Phùng Văn Ngọc

Email: bsphungngoc@gmail.com

Ngày nhận bài: 3.6.2021

Ngày phản biên khoa học: 26.7.2021

Ngày duyệt bài: 4.8.2021

\section{Phùng Văn Ngọc*, Nguyễn Trọng Hưng**}

sectional study involving 220 hypertensive stroke patients was conducted from September 2020 to June 2021 in Neurology Department of Bach Mai hospital. Data were collected through medical records and designed questionnaire. Assessment of MA to antihypertensive drugs was based on Morisky Medication Adherence Scale-8. Result: The average age of patients was $65.13 \pm 11.54$ with male $55 \%$. $20.8 \%, 47.0 \%$ and $32.3 \%$ of patients had poor, moderate and adequate knowledge of hypertension, respectively. The average Morisky-8 score was 4.93 \pm 1.97 . The percentage of MA to antihypertensive drugs amonghypertensive stroke patients was poor, moderate, and high at $59.9 \%, 31.7 \%$ and $8.4 \%$, respectively. Gender, age, health insurance, current smoking, duration of hypertension, and patient's knowledge of hypertension were independently associated with MA among hypertensive stroke patiens. Conclusion: The poor MA to antihypertensive drugs among hypertensive stroke patientsaccounted for a high rate (59.9\%). Related factors associated independentlywith MA in these patientsinclude: age group over 50, female, health insurance, non-smoker, duration of hypertension over 5 years, and good understanding of hypertension.

Keyword: Medication adherence, Stroke, Hypertension, MoriskyMedication Adherence Scale-8

\section{I. ĐĂT VẤN ĐỀ}

Tai biến mạch máu não (TBMN) hiện đang là vấn đề thời sự với nền y học thế giới, là một trong những nguyên nhân gây tử vong và tàn tật hàng đâu. Có nhiều yếu tố nguy cơ của tai biến mạch máu não, trong đó tăng huyết áp (THA) là một yếu tố nguy cơ thường gặp nhất. Nhiêu nghiên cứu đã chỉ ra rằng kiểm soát tốt huyết áp bằng thuốc sẽ làm giảm tỷ lệ mắc TBMN ở cả hai giới và mọi lứa tuổi [1]. Kiểm soát huyết áp bao gồm các vấn đề dùng thuốc và không dùng thuốc, trong đó việc dùng thuốc đóng vai trò quan trọng. Tỷ lệ kiểm soát huyết áp trong các nghiên cứu trên thế giới và tại Việt Nam còn thấp. Các nghiên cứu về tuân thủ thuốc điêuu trị THA trước nay ở Việt Nam mới chỉ tập trung vào THA tại cộng đồng, chưa có nhiều nghiên cứu 
trực tiếp trên nhóm bệnh nhân bị TBMN. Vì vậy, chúng tôi tiến hành nghiên cứu vớimục tiêu:

1. Mô tả sự tuân thủ thuốc điều trị THA ở ngườ bệnh TBMN.

2. Phân tích một số yếu tố liên quan đến mức độ tuân thủ thuốc điều trị THA ở người bệnh TBMN.

\section{II. ĐỐI TƯợNG VÀ PHƯƠNG PHÁP NGHIÊN CỨU}

\section{1 Đối tượng nghiên cứu}

- 202 bệnh nhân được chẩn đoán TBMN có tiền sử THA điều trị tại Bệnh viện Bạch Mai từ 9/2020-6/2021

- Tiêu chuẩn lựa chọn: Bệnh nhân được chẩn đoán TBMN lựa chọn vào nghiên cứu theo tiêu chuẩn của WHO

- Tiêu chuẩn loại trừ: Bệnh nhân không có khả năng trả lời phỏng vấn và bệnh nhân không đồng ý tham gia nghiên cứu.

\subsection{Phương pháp nghiên cứu}

- Thiết kế nghiên cứu: Nghiên cứu mô tả cắt ngang

- Cõ̃ mẫu: Sử dụng công thức tính cỡ mẫu ước lượng một tỷ lệ

$$
n=\frac{Z_{1-\frac{\alpha}{2}}^{2} \cdot p \cdot(1-p)}{d^{2}}
$$

Trong đó: $\mathrm{n}$ : cõ̃ mẫu; d là độ chính xác mong muốn, sai số tối đa cho phép $d=0,05$

$p=0,5$ (dự đoán tỷ lệ tuân thủ thuốc điêuu trị THA trong nghiên cứu là 50\%)

$$
Z_{1-\frac{\alpha}{x}}^{2}=1,96 \text { (mức ý nghĩa } \mathrm{a}=0,05 \text { ) }
$$

Theo công thức trên tính được $n=196$; ước tính thêm với $5 \%$ đối tượng từ chối tham gia, chúng tôi lấy được cõ̃ mẫu 202 bệnh nhân.

- Tất cả các bệnh nhân sau khi được xác định là bị TBMN, có tiền sử chẩn đoán và điều trị THA bằng thuốc đủ tiêu chuẩn nghiên cứu và không có các tiêu chuẩn loại trừ sẽ được thu thập các thông tin về hành chính, thăm khám và phỏng vấn bằng bảng câu hỏi được thiết kế sẵn.

- Nội dung nghiên cứu:

+ Mô tả các đặc điểm chung về dân số học, đặc điểm lâm sàng về điều trị THA

+ Đánh giá mức độ tuân thủ thuốc điều trị THA theo thang điểm Morisky-8 với điểm số từ 0 đến 5 được đánh giá là không tuân thủ, từ 6 đến 8 được đánh giá là tuân thủ điều trị thuốc.

+ Phân tích một số yếu tố liên quan đến tuân thủ thuốc điều trị THA ở người bệnhTBMN

\section{Thang điểm tuân thủ thuốc MMAS - 8}

1./ Ông/ bà có đôi lúc quên uống thuốc không? 2./ Người ta đôi khi bỏ uống thuốc vì một vài lý do khác với quên. Nhớ về hai tuần trước đây, có ngày nào ông/ bà không dùng thuốc không? 3./ Ông/ bà có từng bỏ hay ngưng uống thuốc mà không báo bác sĩ vì ông/ bà cảm thây mệt khi dùng thuốc?

4./ Khi ông/ bà đi du lịch, đi chơi, có đôi lúc ông/ bà quên mang theo thuốc không?

5./ Ông/ bà có uống đủ thuốc ngày hôm qua không?

6./ Khi ông/ bà cảm thấy không kiểm soát triệu chứng của mình, có đôi lúc ông/ bà không uống thuốc không?

7./ Uống thuốc mối ngày thật sự bất tiện với một số người. Ông/ bà có thẩy bất tiện khi phải tuân theo kế hoạch điều trị khônng?

8./ Ông/ bà có thường xuyên thấy khó khăn khi phải nhớ uống tất cả thuốc không?

- A. Không bao giờ/ hiếm - B. Đôi khi

- C. Thinh thoảng

- D. Thường xuyên - E. Luôn luôn

\begin{tabular}{|c|c|}
\hline Mức độ tuân thủ & Điếm \\
\hline Tuân thủ cao & 8 \\
\hline Tuân thủ trung bình & $6-7$ \\
\hline Tuân thủ thấp & $<6$ \\
\hline
\end{tabular}

2.3. Xử lý số liệu: Theo phương pháp thống kê y học, sử dụng phần mềm SPSS 20.0

\section{KẾT QUẢ NGHIÊN CỨU}

3.1 Đặc điểm chung của nhóm nghiên cứu. Nghiên cứu được tiến hành trên 202 bệnh nhân với tuổi trung bình là $65,13 \pm 11$. Nhóm tuổi dưới 50 có 19 bệnh nhân chiếm 9,4\%; nhóm tuổi 50-70 tuổi có 115 bệnh nhân chiếm $56,9 \%$ và trên 70 tuổi có 68 bệnh nhân chiếm 33,7\%. Có $111(55,5 \%)$ nam và 91 (45,5\%) nữ. Dân tộc Kinh có 194 bệnh nhân chiếm 96,0\%. Nhóm trình độ học vấn tiểu học $(37,1 \%)$ và trung học cơ sở $(35,1 \%)$ có tỷ lệ cao nhất. Về nghề nghiệp, tỷ lệ thất nghiệp, làm ruộng, công nhân viên chức, hưu trí lần lượt là $18(8,9 \%), 86(42,6 \%), 44$ $(21,8 \%)$ và $54(26,7 \%)$. Tỷ lệ bệnh nhân tham gia bảo hiểm y tế là $174(86,1 \%)$

3.2 Đặc điểm lâm sàng liên quan điêu trị THA ở bệnh nhân TBMN có THA

Bảng 3.2 Đặc điểm lâm sàng

\begin{tabular}{|ccc|}
\hline Đặc điếm & Số lượng (n) & Tỷ lệ (\%) \\
\hline \multicolumn{3}{|c|}{ Thời gian mắc THA } \\
< 1 năm & 45 & 22,3 \\
$1-5$ năm & 83 & 41,1 \\
$5-10$ năm & 46 & 22,8 \\
$\geq 10$ năm & 28 & 13,9 \\
\hline \multicolumn{3}{|c|}{ Phân độ THA } \\
THA đô̂ I & 40 & 19,8 \\
THA đồ II & 106 & 52,5 \\
THA độ III & 56 & 27,7 \\
\hline \multicolumn{3}{|c|}{ Nhóm thuốc } \\
\hline
\end{tabular}




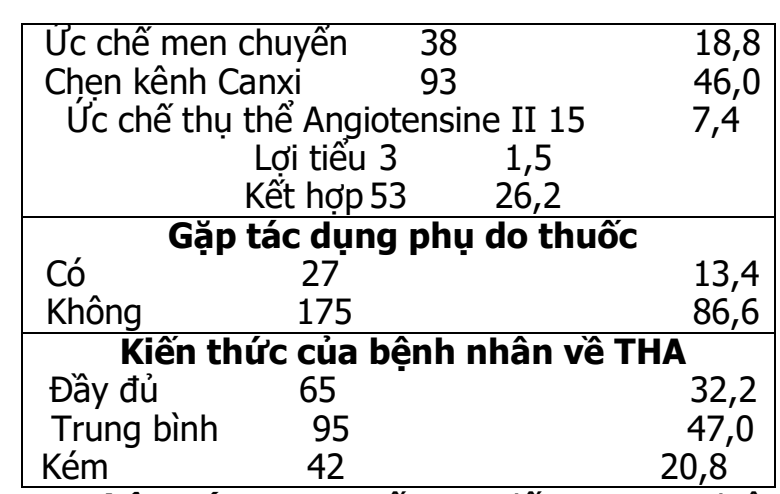

Nhật xét: Trong số 202 đối tượng nghiên cứu, nhóm có thời gian bị THA từ 1-5 năm chiếm đa số (41,1\%); chủ yếu THA giai đoạn II với 106 (52,5\%) bệnh nhân. Nhóm thuốc được kê đơn nhiêu nhất là chẹn kênh Canxi với 46,0\%. Có 27 bệnh nhân (13,4\%) gặp vấn đề tác dụng phụ khi dùng thuốc. Sự hiểu biết của người bệnh về THA các mức độ đầy đủ, trung bình và kém lần lượt là $32,2 \% ; 47,0 \%$ và $20,8 \%$

\subsection{Mức đô tuân thủ thuốc điêu trị THA} THA

Bảng 3.3 Mức độ tuân thủ thuốc điều trị

\begin{tabular}{|c|c|}
\hline Nội dung & Kết quả \\
\hline Điếm Morisky-8 trung bình & $4,93 \pm 1,97$ \\
\hline Tỷ lệ tuân thử thuốc $\mathrm{n}(\%)$ & \\
Thấp & $121(59,9)$ \\
Trung bình & $64(31,7)$ \\
Cao & $17(8,4)$ \\
\hline
\end{tabular}

Nhận xét: Điểm Morisky-8 đánh giá mức độ tuân thủ thuốc trung bình là $4,93 \pm 1,97$. Có 121 người bênh không tuân thủ điều trị $(59,9 \%)$; mức độ trung bình 31,7\%; tuân thủ cao có 8,4\%.

\subsection{Các yếu tố ảnh hưởng đến tuân thủ thuốc điêuu trị THA}

Bảng 3.4 Các yếu tố ảnh hưởng đến tuân thủ thuốc điều trị THA

\begin{tabular}{|c|c|c|c|}
\hline \multirow[b]{2}{*}{ Yếu tố } & \multicolumn{2}{|c|}{ n (\%) } & \multirow[b]{2}{*}{$\mathbf{p}$} \\
\hline & Tuân thủ & Không tuân thủ & \\
\hline $\begin{array}{cl}\text { Tuối : } & <50 \\
& 50-70 \\
& >70\end{array}$ & $\begin{array}{c}2(2,5 \%) \\
50(61,7 \%) \\
29(35,7 \%)\end{array}$ & $\begin{array}{l}17(14,0 \%) \\
65(53,7 \%) \\
39(32,3 \%)\end{array}$ & 0,022 \\
\hline $\begin{array}{ll}\text { Giới tính: } & \begin{array}{l}\text { Nam } \\
N \tilde{u}^{\prime}\end{array}\end{array}$ & $\begin{array}{l}37(45,7 \%) \\
44(54,3 \%)\end{array}$ & $\begin{array}{l}74(61,2 \%) \\
47(38,8 \%)\end{array}$ & 0,043 \\
\hline 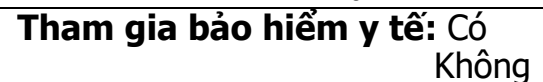 & $\begin{array}{c}78(96,3 \%) \\
3(3,7 \%)\end{array}$ & $\begin{array}{l}96(79,3 \%) \\
25(20,7 \%)\end{array}$ & 0,001 \\
\hline Hút thuốc lá: $\begin{array}{c}\text { Có } \\
\text { Không }\end{array}$ & $\begin{array}{l}16(19,8 \%) \\
65(80,2 \%)\end{array}$ & $\begin{array}{l}50(41,3 \%) \\
71(58,7 \%)\end{array}$ & 0,002 \\
\hline $\begin{array}{c}\text { Thời gian bị THA: }<1 \text { năm } \\
1-5 \text { năm } \\
5-10 \text { năm } \\
>10 \text { năm }\end{array}$ & $\begin{array}{l}10(12,3 \%) \\
32(39,5 \%) \\
25(30,9 \%) \\
14(17,3 \%)\end{array}$ & $\begin{array}{l}35(28,9 \%) \\
51(42,1 \%) \\
21(17,4 \%) \\
14(11,6 \%)\end{array}$ & 0,011 \\
\hline $\begin{array}{c}\text { Kiến thức về THA: Kém } \\
\text { Trung bình } \\
\text { Đầy đủ }\end{array}$ & $\begin{array}{c}0(0 \%) \\
27(33,3 \%) \\
54(60,7 \%)\end{array}$ & $\begin{array}{c}42(34,7 \%) \\
68(56,2 \%) \\
11(9,1 \%)\end{array}$ & $<0,001$ \\
\hline
\end{tabular}

Nhận xét: Các yếu tố ảnh hưởng đến việc tuân thủ thuốc bao gồm: Tuổi $(p=0,022)$; giới tính ( $p=0,043)$; tham gia BHYT $(p=0,001)$; tình trạng hút thuốc lá hiện tại $(p=0,002)$; thời gian bị THA $(p=0,011)$; hiểu biết của người bệnh về THA $(p<0,001)$

3.5 Mô hình hồi qui logistic các yếu tố ảnh hưởng đến tuân thủ điêu trị

Bảng 3.5 Mô hình hồi qui logistic các yếu tố ảnh hưởng đến tuân thủ điều trị

\begin{tabular}{|c|c|c|c|}
\hline \multicolumn{2}{|c|}{ Yếu tố } & OR (95\% CI) & \multirow{3}{*}{$\begin{array}{c}\mathbf{p} \\
\text { Tham chiếu } \\
\mathbf{0 , 0 3 1}\end{array}$} \\
\hline Giới & Nam & 1,000 & \\
\hline Giol & Nũ̃ & $1,872(1,059-3,310)$ & \\
\hline \multirow{3}{*}{ Tuổi } & $<50$ & 1,000 & \multirow{3}{*}{$\begin{array}{c}\text { Tham chiế } \\
\mathbf{0 , 0 1 5} \\
\mathbf{0 , 0 1 9}\end{array}$} \\
\hline & $50-70$ & $6,538(1,443-29,623)$ & \\
\hline & $>70$ & $6,321(1,352-29,541)$ & \\
\hline \multirow{2}{*}{$\begin{array}{c}\text { Tham gia bảo } \\
\text { hiểm y tế }\end{array}$} & Có & $6,757(1,972-23,256)$ & \multirow{2}{*}{$\begin{array}{c}\mathbf{0 , 0 0 2} \\
\text { Tham chiếu }\end{array}$} \\
\hline & Không & 1,000 & \\
\hline \multirow{2}{*}{ Hút thuốc lá } & Có & 1,000 & \multirow{2}{*}{$\begin{array}{c}\mathbf{0 , 0 0 2} \\
\text { Tham chiếu }\end{array}$} \\
\hline & Không & $2,862(1,485-5,512)$ & \\
\hline \multirow{2}{*}{ Thời gian bị THA } & $<1$ năm & 1,000 & Tham chiếu \\
\hline & $1-5$ năm & $2,196(0,957-5,037)$ & 0,063 \\
\hline
\end{tabular}


TAP CHÍ Y HOC VIÊT NAM TÂP 505 - THÁNG 8 - SỐ 2 - 2021

\begin{tabular}{|c|c|c|c|}
\hline & $5-10$ năm & $4,167(1,675-10,365)$ & $\mathbf{0 , 0 0 2}$ \\
\cline { 2 - 3 } & $>10$ năm & $3,500(1,261-9,717)$ & $\mathbf{0 , 0 1 6}$ \\
\hline \multirow{2}{*}{ Hiểu biết về THA } & Đây đủ & 1,000 & \multirow{2}{*}{ Tham chiếu0,997 } \\
\cline { 2 - 3 } & Trung bình & $0,035(0,013-2,67)$ & $\mathbf{0 , 0 0 1}$ \\
\cline { 2 - 3 } & Kém & $0,081(0,037-0,178)$ & \\
\hline
\end{tabular}

Nhận xét: Nữ giới có mức độ tuân thủ thuốc cao gấp 1,872 lần so với nam giới (KTC $95 \%$ $1,059-3,310 ; p=0,031)$. Việc tham gia bảo hiểm y tế có mức độ tuân thủ cao gấp 6,757 lần so với không tham gia bảo hiểm y tế (KTC 95\% 1,97223,256; $p=0,002$ ). Nhóm tuổi trên 50 tuổi tuân thủ điều trị thuốc hơn nhóm tuổi dưới 50 tuổi. Những người không hút thuốc tuân thủ điều trị gấp 2,862 lần so với nhóm hút thuốc. Nhóm người bệnh mới mắc THA trong vòng 5 năm đầu có mức độ tuân thủ điều trị THA kém hơn so với các nhóm trên 5 năm. Nhóm người bệnh có kiến thức kém về THA có mức tuân thủ điều trị THA cao hơn 0,081 lần so với nhóm có kiến thức tốt về THA.

\section{BÀN LUÂ̂N}

Nghiên cứu của chúng tôi tiến hành trên 202 người bệnh với $81(40,1 \%)$ người tuân thủ điêu trị và 121 (59,9\%)người không tuân thủ điều trị. Tỷ lệ tuân thủ này thấp hơn so với nghiên cứu ở các nước đã phát triển như Mỹ $(51,3 \%)$ [2], Đức $(56,3 \%)[3]$, Anh $(58,4 \%)$ [4] nhưng cao hơn so với nghiên cứu của ở Trung Quốc như Pan J. $(35,23 \%)$ [5], Xu J. (31,6\%) [6]. Sự khác biệt này do khác biệt về cỡ mẫu, vùng địa lý kinh tế nơi sống. Các nghiên cứu ở Trung Quốc tiến hành tai vùng Tây Bắc là nơi có mức độ kinh tế, dân trí thấp [7]. Kết quả của chúng tôi cũng tương tự như trong nghiên cứu của Vũ Xuân Phú với 44,8\% đối tượng tuân thủ điều trị [8].

Về các yếu tổ độc lập có liên quan đến việc tuân thủ điêu trị THA của người bệnh TBMN có THA, chúng tôi ghi nhận có các yểu tố về tuổi, giới, việc tham gia bảo hiểm y tế, thời gian bị THA, tình trạng hút thuốc hiện tại và sự hiểu biết của người bệnh về THA. Nhóm tuổi dưới 50 tuổi có xu hướng ít tuân thủ điều trị so với nhóm tuổi trên 50 tuổi, tương đồng trong nghiên cứu của Vũ Xuân Phú; lý do là nhóm tuổi trên 50 , công việc ổn định hoặc trong độ tuổi hưu trí nên có nhiều thời gian quan tâm đến sức khỏe của mình hơn [8].

Về giới, nghiên cứu của chúng tôi cho thấy giới nữ tuân thủ điều trị cao hơn nam giới là 1,872 lần. Kết quả này tướng tự với nghiên cứu ở Trung Quốc, Liban và cuat tác giả Vũ Xuân Phú (Việt Nam) [8]. Giải thích cho điêu này có thể do nữ giới thường quan tâm nhiều hơn tới sức khỏe của cá nhân mình so với nam giới; đối với nam giới là đối tượng hay uống rượu, bia và hút thuốc lá... chưa thường xuyên chú trọng đến sức khỏe bản thân. Đây chính là những yếu tố nguy cơ cho THA. Nghiên cứu cũng chỉ ra rằng những người hiện đang hút thuốc có mức độ tuân thủ kém hởn nhóm không hút thuốc 2,8 lần.

Việc tham gia bảo hiểm y tế cũng góp phần làm tằng tính tuân thủ thuốc 6,7 lần theo nghiên cứu của chúng tôi. Ở nước ta, bảo hiểm y tế là môt hình thức bảo hiểm do Nhà nước đưa ra nhằm mục đích chăm sóc sức khỏe cộng đồng, không vì mục đích lợi nhuận. Bảo hiểm y tế sẽ chi trả chi phí khám chữa bệnh cho người tham gia, điều này thúc đẩy người bênh thường xuyên đi khám chữa bệnh, được tư vấn sức khỏe thường xuyên bởi các nhân viên y tế... vì lẽ đó mà họ sẽ tuân thủ thuốc hơn so với người không có bảo hiểm y tế, không được khám định kỳ thường xuyên theo chế độ bảo hiểm y tế.

Nghiên cứu của chúng tôi chỉ rằng nhóm đối tượng mới bị THA trong vòng 1 năm kém tuân thủ hơn nhóm bi THA từ $5-10$ năm $(p=0,002$; $\mathrm{OR}=4,167 ; \mathrm{CI}=1,675-10,365)$ và trên 10 năm $(\mathrm{p}=0,016 ; \mathrm{OR}=3,5 ; \mathrm{CI}=1,261-9,717)$ có ý nghĩa thống kê với $a=0,05$. Điều này có thể do những đối tượng mới mắc chưa tìm hiểu nhiều về THA. Tuy nhiên trong nghiên cứu của Vũ Xuân Phú không có sự khác biệt về tuân thủ điều trị ở hai nhóm đối tượng bị THA dưới 1 năm và nhóm trên 1 năm [8]. Sự khác biệt này là do cách phân nhóm đối tượng khác nhau, cần thêm nghiên cứu để chứng minh điều này.

Bên cạnh đó, chúng tôi thãy có mối liên quan giữa sự hiểu biết về bênh THA với sự tuân thủ thuốc điều trị THA, những nhóm đối tượng có kiến thức đầy đủ về THA thì tuân thủ tốt hơn 0,081 lần so với nhóm có kiến thức không đầy đủ về THAcó ý nghĩa thống kê với $a=0,05(p<$ $0,001 ; \mathrm{OR}=0,081)$. Kết quả này tương đồng với nghiên cứu của Pan J. và của Vũ Xuân Phú [5],[8]. Chỉ khi hiểu rõ về bệnh, cách điều trị, các biến chứng có thể xảy ra nếu không điều trị thì người bệnh mới thực sự tuân thủ điều trị.

\section{KẾT LUẬN}

Qua nghiên cứu sự tuân thủ điều trị THA ở 202 người bệnh TBMN có THA, chúng tôi thây điểm Morisky-8 trung bình cho việc tuân thủ 


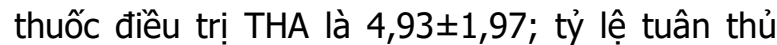
điều trị THA ở mức độ thấp là $59,9 \%$, mức trung bình là $31,7 \%$ vàmức cao là $8,4 \%$. Các yếu tố có liên quan độc lập đến việc tuân thủ thuốc THA bao gồm: nhóm tuổi trên 50, nữ giới, tham gia bảo hiểm y tế, không hút thuốc lá, thời gian mắc THA trên 5 năm và sự hiểu biết đầy đủ của người bệnh về THA.

\section{TÀI LIẸU THAM KHẢO}

1. Katsanos A.H., Filippatou A., Manios E., et al. (2017). Blood Pressure Reduction andSecondary Stroke Prevention: A Systematic Review and Metaregression Analysis of Randomized Clinical Trials. Hypertension, 69(1), 171-179.

2. Gupta P., Patel P., Strauch B., et al. (2017) Risk Factors for Nonadherence to Antihypertensive Treatment. Hypertension, 69(6), 1113-1120.

3. Langagergaard V., Palnum K.H., Mehnert F., et al. (2011). Socioeconomic differences in quality of care and clinical outcome after stroke: a nationwide population-based study. Stroke, 42(10), 2896-2902.

4. Schulz M., Krueger $K_{.}$, Schuessel $K_{.}$, et al. (2016). Medication adherence and persistence according to different antihypertensive drug classes: A retrospective cohort study of 255,500 patients. Int J Cardiol, 220, 668-676.

5. Pan J., Lei T., Hu B., et al. (2017). Postdischarge evaluation of medication adherence and knowledge of hypertension among hypertensive stroke patients in northwestern China. Patient Prefer Adherence, 11, 1915-1922.

6. Xu J., Zhao X., Wang Y., et al. (2013). Impact of a better persistence with antihypertensive agents on ischemic stroke outcomes for secondary prevention. PLoS One, 8(6), e65233.

7. Lee G.K.Y., Wang H.H.X., Liu K.Q.L., et al. (2013). Determinants of medication adherence to antihypertensive medications among a Chinese population using Morisky Medication Adherence Scale. PLoS One, 8(4), e62775.

8. Vũ Xuân Phú và Cs. (2012). Nghiên cứu một sỗ yếu tố liên quan với tuân thủ điều trị tăng huyết áp ở bênh nhân 25-60 tuổi tai 4 phường thành phố Hà Nội, năm 2011. Tạp chí Y học thực hành, số 5, 47-51.

9. Ois A., Gomis M., Rodríguez-Campello A., et al. (2008). Factors Associated With a High Risk of Recurrence in Patients With Transient Ischemic Attack or Minor Stroke. Stroke, 39(6), 1717-1721.

\title{
MÔ TẢ ĐĂC ĐIỂM LÂM SÀNG, SINH HỌC Ở BÊNH NHÂN GIẢM TIỂU CẦU MIỄN DİCH NGƯờI LớN Có HIỆN DIỆN KHÁNG THỂ KHÁNG NHÂN (ANA)
}

\author{
Nguyễn Thị Ngọc Sang1,2, Trần Thị Mỹ Duyên²,
} Suzanne Monivong Cheanh Beaupha ${ }^{1,2}$

\section{TÓM TẮT}

Mục tiêu: Mô tả đăc điểm lâm sàng, sinh hoc, điều trị ban đầu ở hai nhóm bệnh nhân giảm tiểu cầu miễn dich người lớn có xét nghiẹm kháng thể kháng nhân (ANA) dương và âm tính. Đối tượng: Bệnh nhân $(B N)>15$ tuổi giảm tiểu câu miễn dich mới chẩn đoán đ̛ược nhập viện vào khoa Huyết học bệnh viện Chơ Rẫy trong khoảng thời gian 02/2020 đến 07/2021, được làm xét nghiệm ANA trong quá trình tiếp cận chẩn đoán. Thiết kế nghiên cứu: Nghiên cứu mô tả hàng loạt ca, hồi cứu và tiến cứu. Kết quả: 149 bệnh nhân thỏa tiêu chuẩn chon mẫu được đưa vào nghiên cứu. Tỉ lệ nam/nữ là 1/2,46. Tuổi trung bình là 46,56 tuổi. Tỉ lề xuất huyết lúc nhập viện là $94 \%$, thướng nhất là độ II chiếm $60,4 \%$, xuất huyết năng độ IV chiếm $10,7 \%$. Phần lớn BN nhập viện có xuất huyểt da với $88,7 \%$, kế tiếp là xuất huyết niêm mac $48,9 \%$. Trong nghiên cứu cũng ghi nhận $7 / 149$ (5\%) BN xuất huyết não được xác nhận bằng CT scan sọ não. $49 \%$

${ }^{1}$ Đại học Y dược thành phố Hồ Chí Minh

2Bềnh viên Chơ Rẫy

Chịu trách nhiệm chính: Nguyễn Thị Ngọc Sang

Email: sangnguyen163@gmail.com

Ngày nhân bài: 2.6.2021

Ngày phản biên khoa hoc: 26.7.2021

Ngày duyệt bài: 4.8 .2021
BN nhâp viện với tình trang thiếu máu. 40/149 $(26,8 \%)$ BN có xét nghiệm ANA dương tính. 2/143 $(1,4 \%)$ BN dương tính với anti DsDNA, đồng thời cũng dương tính với $\mathrm{ANA}$. Số $\mathrm{BN}$ giảm $\mathrm{C} 3$ và $\mathrm{C} 4$ lần lượt là $10 / 125(8 \%)$ và $13 / 125(10,4)$. Không ghi nhận khác biệt về giới tính, độ tuổi, bệnh nền, vị trí xuất huyết, số lượng tiểu câu, số ngày nằm viện và số đớn vị chế phẩm máu cần truyền. Yếu tố liên quan với giảm tiểu cầu miễn dịch (ITP) có hiện diện ANA được xác định là mức độ xuất huyết, thiếu máu và nồng đô Hemoglobin. Kết luận: Tỉ lệ dương tính của xét nghiêm ANA trong ITP mới chẩn đoán là $26,8 \%$ (95\%CI:19,9-34,7\%), nhiều nhất trong các xét nghiêm tầm soát bênh tư miễn trong nghiên cứu (ANA, anti DsDNA, C3, C4). Những BN có hiện diện ANA có tỉ lê xuất huyết năng nhiều hơn, thiếu máu lúc nhập viện nhiều hơn và nồng độ Hemoglobin thấp hơn.

Tư khóa: Giảm tiểu cầu miễn dich (ITP) mới chẩn đoán, ANA, anti DsDNA

\section{SUMMARY \\ DESCRIBE CLINICAL, BIOLOGICAL OF ELEVATED ANTINUCLEAR ANTIBODY TEST IN ADULT PATIENTS WITH IMMUNE THROMBOCYTOPENIC PURPURA}

